\title{
Avaliação da qualidade da água do Ribeirão Samambaia (São Pedro, São Paulo, Brasil) através de parâmetros físicos e químicos, índice de estado trófico e teste de toxicidade com Daphnia magna
}

\author{
Water quality assessment in Samambaia Creek (São Pedro, São Paulo, Brazil) \\ through physical chemical parameters, trophic state index and toxicity test \\ with Daphnia magna
}

\begin{abstract}
Lucineide Aparecida Maranho', Rafael Grossi Botelho², Larissa de Assunção Nogueira ${ }^{3}$, Valdemar Luiz Tornisielo ${ }^{4}$
\end{abstract}

$\square$

\section{RESUMO}

O objetivo deste trabalho foi avaliar a qualidade da água do Ribeirão Samambaia (São Pedro, São Paulo, Brasil) utilizando parâmetros físicos e químicos, índice de estado trófico (IET) e ensaio ecotoxicológico com Daphnia magna. De janeiro a dezembro de 2011, amostras de água foram coletas mensalmente à montante e à jusante de São Pedro e dentro da cidade, e expostas a D. magna em laboratório durante 48 horas para avaliar efeitos sobre sua mobilidade. Condutividade, fenóis, oxigênio dissolvido, demanda bioquímica de oxigênio, surfactantes, pH e IET foram mensurados. Valores dos cinco primeiros parâmetros demonstraram baixa qualidade da água à jusante da cidade. Valores de clorofila-a estiveram dentro do permitido pela legislação ambiental brasileira e, dessa forma, O IET das águas do Ribeirão Samambaia foi classificado como ultraoligotrófico para a maioria dos locais e meses amostrados. Amostras de água coletadas de janeiro a abril à jusante de São Pedro foram tóxicas para D. magna. De acordo com as características físicas e químicas e o ensaio ecotoxicológico, conclui-se que o Ribeirão Samambaia possui baixa qualidade da água após a cidade de São Pedro. Palavras-chave: ensaio ecotoxicológico; microcrustáceos; mobilidade; qualidade da água. 口

\section{INTRODUÇÃO}

A urbanização é um processo natural que tem sido constantemente acompanhado pela diminuição da qualidade da água de um curso hídrico (WALSH; FLETCHER; LADSON, 2005), e por isso, nos últimos anos o foco sobre os impactos causados por descargas de efluentes domésticos nesses ambientes tem aumentado.

\begin{abstract}
The goal of this study was to evaluate the water quality of Samambaia Creek (São Pedro, São Paulo, Brazil) through physical chemical parameters, trophic state index (TSI) and ecotoxicological assay with Daphnia magna. From January to December 2011 water samples were monthly collected from upstream, downstream and inside the São Pedro city, and exposed to D. magna in laboratory for 48 hours to evaluate mobility effects. Conductivity, phenols, dissolved oxygen, biochemical oxygen demand, surfactants, pH, and TSI were measured. Values of the first five parameters showed low water quality downstream of the city. Chlorophyll a values were within the range permitted by the Brazilian environmental legislation and thus the TSI in Samambaia Creek was classified as ultra-oligotrophic for most sites and months. Water samples collected from January to April downstream of São Pedro were toxic to D. magna. The physical chemical analysis and the toxicity test indicate low quality of water from Samambaia Creek downstream the city of São Pedro.
\end{abstract}

Keywords: ecotoxicological assay; microcrustaceans; mobility;water quality.

A preservação dos recursos hídricos requer um monitoramento adequado através de técnicas que sejam capazes de identificar o real estado da qualidade da água, e para esse propósito, a determinação de parâmetros físicos e químicos tem sido utilizada. No entanto, para alguns autores como Cairns Junior (2002), a caracterização física e química deve ser realizada em conjunto com ensaios ecotoxicológicos utilizando

'Doutora em Química na Agricultura e no Ambiente pela Universidade de São Paulo (USP) - Piracicaba (SP), Brasil. 2Doutor em Química na Agricultura e no Ambiente pela USP - Piracicaba (SP), Brasil.

${ }^{3}$ Graduada em Ciências Biológicas pela Universidade Metodista de Piracicaba (UNIMEP) - Piracicaba (SP), Brasil.

${ }^{4}$ Professor Livre Docente do Centro de Energia Nuclear na Agricultura da USP - Piracicaba (SP), Brasil.

Endereço para correspondência: Valdemar Luiz Tornisielo - Avenida Centenário, 303 - São Dimas - 13416-O0O - Piracicaba (SP), Brasil - E-mail: vltornis@cena.usp.br Recebido: 10/02/14 - Aceito: 01/06/16 - Reg. ABES: 130372 
organismos vivos, já que esses interagem com os poluentes, e dessa forma os resultados são mais próximos da realidade, conforme mostram os estudos de Palma et al. (2010), Botelho et al. (2012) e Botelho et al. (2013).

Outro parâmetro que tem sido mensurado no monitoramento da qualidade dos ambientes aquáticos tem sido a eutrofização, pela determinação do índice de estado trófico (IET). De acordo com Vieira et al. (2013), a eutrofização, que se refere ao enriquecimento por nutrientes (principalmente nitrogênio e fósforo) e matéria orgânica, tem sido um dos principais problemas relacionados à qualidade das águas. Juma, Wang, Li (2014) observaram que o crescimento populacional entre 1990 e 2012 acelerou o processo de eutrofização no Lago Vitória, localizado no Quenia, África Oriental. Algumas características, tais como crescimento de algas, altas concentrações de nitrogênio e fósforo, e diminuição do oxigênio dissolvido, foram observadas.

Cladóceros, especialmente os dafinidios, têm sido mundialmente utilizados como organismos teste em estudos de avaliação da qualidade de ambientes aquáticos (PALMA et al., 2014), sendo a principal razão para isso sua sensibilidade, facilidade de cultivo e biologia conhecida. Dentre os cladóceros, a Daphnia magna é utilizada em testes de toxicidade desde a década de 1940 (ANDERSON, 1944), pois, além de reunir todas as características citadas anteriormente, é padronizada por agências nacionais e internacionais para esse propósito (ABNT, 2003; OECD, 2012).

São Pedro está localizada no setor centro-leste do estado de São Paulo e situa-se entre as coordenadas $22^{\circ} 41^{\prime}$ e $22^{\circ} 26^{\prime}$ latitude sul e $48^{\circ} 05^{\prime}$ e $47^{\circ} 47^{\prime}$ longitude oeste. O município abrange uma área de $596 \mathrm{~km}^{2}$ e limita-se ao norte com Itirapina e Torrinha, a oeste com Santa Maria da Serra, e ao sul com Piracicaba. A rede hidrográfica está representada pelo Rio Piracicaba e seus inúmeros afluentes, dentre eles o Ribeirão Samambaia. O município tem como economia principal a produção agropecuária, com destaque para gado de leite e corte e o cultivo de cana-de-açúcar (CARPI JUNIOR; CARRARA; BISCALCHIM NETTO, 2010).

Diversos estudos têm sido realizados em rios e ribeirões da região centro-leste do estado de São Paulo com o objetivo de avaliar a qualidade desses ambientes. Nesse sentido, merecem destaques o estudo de Jardim, Armas e Monteiro (2008), que avaliaram a qualidade da água e do sedimento do Rio Corumbataí através de teste de toxicidade aguda e crônica com D. magna e D. similis. Botelho et al. (2012) avaliaram a influência de uma indústria sucroalcooleira na qualidade da água do Ribeirão Piracicamirim, localizado na cidade de Piracicaba, utilizando parâmetros físicos e químicos e o teste de toxicidade com os microcrustáceos D. magna e Ceriodaphnia dubia, e observaram que a indústria não estava impactando esse ambiente. Em outro estudo, Botelho et al. (2013) avaliaram a qualidade da água do Rio Piracicaba em seis locais de amostragens entre a nascente e sua foz durante um ano. Diversos parâmetros físicos e químicos e organismos teste foram utilizados, e foi observada baixa qualidade da água em locais próximos a grandes cidades como Americana e Piracicaba.
No presente trabalho, o Ribeirão Samambaia foi escolhido como ambiente de estudo, pois, além de não haver estudos realizados nesse curso hídrico, está situado em uma cidade reconhecida pelo governo do estado de São Paulo como uma estância turística. Nesse sentido, o presente estudo teve como objetivo determinar a qualidade de suas águas utilizando parâmetros físicos e químicos, IET e ensaio ecotoxicológico com D. magna.

\section{METODOLOGIA}

\section{Amostragem e parâmetros físicos e químicos}

As amostras de água foram coletadas mensalmente no Ribeirão Samambaia de janeiro a dezembro de 2011 à montante da cidade de São Pedro (ponto 1), na cidade de São Pedro (ponto 2) e à jusante de São Pedro (ponto 3) para análise de oxigênio dissolvido e temperatura (oxímetro YSI 55-12FT), condutividade (condutivímetro Ação Científica MCA - 150 P), pH (phmetro Ação Científica MPA - 210 P) e demanda bioquímica de oxigênio (oxímetro YSI 55). Concentrações de fenóis e surfactantes foram mensuradas de janeiro a julho de 2011 por meio do método colorimétrico de leitura visual utilizando o kit de teste da CHEMets, que apresenta escala de medição de 0 a 3,0 mg.L-1. Todos os parâmetros foram determinados imediatamente após a amostragem. A localização dos locais de amostragens pode ser observada na Figura 1.

Para determinar a demanda bioquímica de oxigênio, a metodologia contida na NBR 12614 da Associação Brasileira de Normas Técnicas (ABNT, 1992) foi seguida. Os resultados de pH, oxigênio dissolvido, condutividade, demanda bioquímica de oxigênio e temperatura da água estão apresentados como média, desvio padrão, máximo e mínimo valor durante o período de amostragem, e coeficiente de variação.

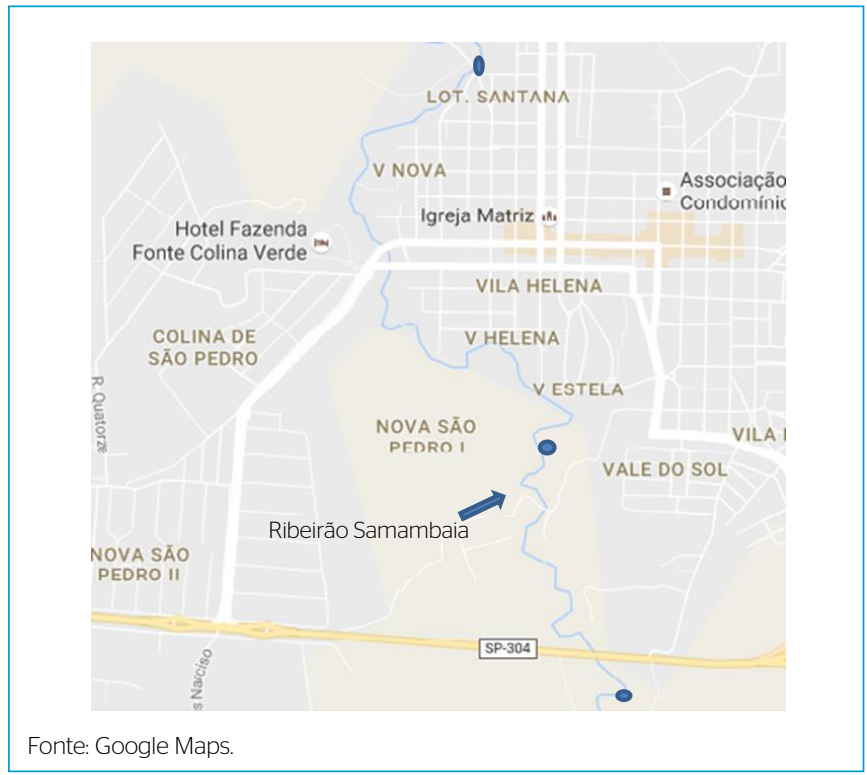

Figura 1 - Localização dos locais de amostragens de água no Ribeirão Samambaia. 


\section{Índice de estado trófico}

Carlson (1977) desenvolveu uma classificação do estado trófico dos ambientes aquáticos baseado em três tipos de parâmetros: concentração de clorofila-a, transparência da água medida pelo disco de Secchi e concentração de fósforo total. Apesar de alguns autores utilizarem os três parâmetros, ou apenas fósforo ou clorofila-a, segundo esse autor, qualquer um deles pode ser utilizado sozinho para tal análise. Assim, neste estudo o IET foi determinado por meio da concentração de clorofila-a.

Para avaliar o estado trófico das águas do Ribeirão Samambaia foi utilizado o índice desenvolvido por Carlson (1997) e adaptado para águas de rios por Lamparelli (2004). Primeiramente, $200 \mathrm{~mL}$ de amostra de água de cada local de amostragem foram filtrados em funil de Büchner contendo filtro de fibra de vidro. Em seguida, os filtros foram congelados por 24 horas a uma temperatura de $-12^{\circ} \mathrm{C}$. Após esse período, os filtros foram colocados em placas de petri, seguidos de adição de $10 \mathrm{~mL}$ de acetona $90 \%$ para a extração dos pigmentos e colocados em geladeira por 24 horas. Todos os procedimentos foram realizados com a menor quantidade de luz possível. Após 24 horas o extrato foi centrifugado por 20 minutos a $3.500 \mathrm{rpm}$ em centrífuga (Backman, J2-HS). Após a centrifugação, o líquido sobrenadante foi retirado e completado com $10 \mathrm{~mL}$ de acetona $90 \%$ para posterior leitura em espectrofotômetro (Hach DR5000) nos comprimentos de onda de 663 e $750 \mathrm{~nm}$. Para o cálculo da concentração de clorofila-a, utilizou-se a Equação 1.

$$
\text { Pclor }=\frac{\text { Eclor } \mathrm{x} 1000 \mathrm{x} \text { Vextr }}{\text { Kclor } \mathrm{x} \text { Vfilt }}
$$

Onde:

Pclor: concentração de clorofila-a $\left(\mu g \mathrm{~L}^{-1}\right)$;

Eclor: leitura corrigida para clorofila-a, sendo Eclor = E663 - E750;

E663: leitura a $663 \mathrm{~nm}$;

E750: leitura a $750 \mathrm{~nm}$;

1000: correção do volume por litro;

Vextr $(\mathrm{mL})$ : volume do extrato $(10 \mathrm{~mL})$;

Kclor: coeficiente de extinção para clorofila-a (89);

Vfilt (L): volume filtrado (em litros).

Posteriormente à determinação da concentração de clorofila-a, foi determinado o IET através da Equação 2.

$$
\operatorname{IET}(\mathrm{CL})=10 \times(6-((-0,7-0,6 \times(\ln C L)) / \ln 2))-20
$$

Onde:

CL: concentração de clorofila-a (em $\left.\mu \mathrm{g} \mathrm{L}^{-1}\right)$;

ln: logaritmo natural.

Os resultados do IET foram comparados utilizando a classificação de acordo com a Tabela 1.

\section{Manutenção e teste de toxicidade com D. magna}

Todos os procedimentos para manutenção e condução do teste de toxicidade foram realizados seguindo a norma NBR 12713 da ABNT (2003). Cultivos de D. magna foram mantidos no Laboratório de Ecotoxicologia do Centro de Energia Nuclear na Agricultura (Piracicaba, São Paulo) em béqueres de $2 \mathrm{~L}$ em incubadora com temperatura controlada em $20 \pm 2^{\circ} \mathrm{Ce}$ fotoperíodo de 16 horas luz e 8 horas escuro. Para manutenção foi utilizada água reconstituída preparada com água ultrapura e reagentes químicos de acordo com a ABNT (2003). Durante a manutenção dos organismos, os valores de $\mathrm{pH}$ e dureza estiveram de acordo com aqueles estabelecidos pela ABNT (2003). A água de manutenção do cultivo foi renovada duas vezes por semana, e os organismos foram alimentados com alga Pseudokirchneriella subcapitata três vezes por semana ( $1 \times 10^{6}$ células por organismo).

Para o teste de toxicidade, foram utilizados organismos com idade entre 6 e 24 horas. Para o preparo das concentrações, utilizou-se a mesma água de manutenção (água de diluição) e essas foram assim estabelecidas: $100,00 \%$ (1:1) (amostra pura), 50,00\% (1:2), 33,34\% (1:3), $25,00 \%$ (1:4), 16,67\% (1:6) e 12,50\% (1:8) (Tabela 2).

Foram utilizadas duas réplicas por concentração, incluindo o grupo controle, com dez organismos em cada (ABNT, 2003). O sistema teste foi acondicionado em câmara de germinação tipo BOD com temperatura controlada $\left(20 \pm 2^{\circ} \mathrm{C}\right)$, sem luminosidade e sem alimentação durante 48 horas. Após o período de exposição, foi observado o efeito

Tabela 1 - Classificação do índice de estado trófico com a ponderação para clorofila-a segundo Lamparelli (2004).

\begin{tabular}{l|c|c} 
Categoria & Ponderação & Clorofila-a $\left(\mu \mathrm{g} . \mathrm{L}^{-1}\right)$ \\
\hline Ultraoligotrófico & $\mathrm{IET} \leq 47$ & $\mathrm{CL} \leq 0,74$ \\
\hline Oligotrófico & $47<\mathrm{EET} \leq 52$ & $0,74 \leq \mathrm{CL} \leq 1,31$ \\
\hline Mesotrófico & $52<\mid \mathrm{ET} \leq 59$ & $1,31 \leq \mathrm{CL} \leq 2,96$ \\
\hline Eutrófico & $59<\mid \mathrm{ET} \leq 63$ & $2,96 \leq \mathrm{CL} \leq 4,70$ \\
\hline Supereutrófico & $63<\mathrm{EET} \leq 67$ & $4,70 \leq \mathrm{CL} \leq 7,46$ \\
\hline Hipereutrófico & $\mathrm{IET}>67$ & $7,46<\mathrm{CL}$ \\
\hline
\end{tabular}

IET: Indice de estado trófico; CL: concentração de clorofila-a.

Tabela 2 - Preparo das concentrações testes utilizadas no ensaio de toxicidade com Daphnia magna.

\begin{tabular}{l|c|c|c|c|c}
$\begin{array}{l}\text { Diluição da } \\
\text { amostra }\end{array}$ & $\begin{array}{c}\text { Fator de } \\
\text { diluição }\end{array}$ & $\begin{array}{c}\text { Amostra } \\
(\mathrm{mL})\end{array}$ & $\begin{array}{c}\text { Água de } \\
\text { diluição } \\
(\mathrm{mL})\end{array}$ & $\begin{array}{c}\text { Volume } \\
\text { final } \\
(\mathrm{mL})\end{array}$ & $\begin{array}{c}\text { Concentração } \\
\text { da solução } \\
\text { teste } \%)\end{array}$ \\
\hline Controle & - & - & 50,00 & 50,00 & - \\
\hline $1: 1$ & 1 & 50,00 & - & 50,00 & 100,00 \\
\hline $1: 2$ & 2 & 25,00 & 25,00 & 50,00 & 50,00 \\
\hline $1: 3$ & 3 & 16,67 & 33,33 & 50,00 & 33,34 \\
\hline $1: 4$ & 4 & 12,50 & 37,50 & 50,00 & 25,00 \\
\hline $1: 6$ & 6 & 8,33 & 41,67 & 50,00 & 16,67 \\
\hline $1: 8$ & 8 & 6,25 & 43,75 & 50,00 & 12,50 \\
\hline
\end{tabular}


das amostras de água sobre a mobilidade de D. magna. Foram considerados imóveis os organismos incapazes de nadar na coluna de água até 15 segundos após uma leve agitação do recipiente teste.

De acordo com Knie e Lopes (2004), o valor de fator de toxicidade para daphnias é observado na diluição teste, não sendo necessário cálculo estatístico, e corresponde à menor diluição da amostra em que não ocorreu imobilidade em mais de $10 \%$ dos organismos. Ainda segundo esses autores, os resultados são expressos em números inteiros, igual ao fator de diluição da amostra. Nesse caso, as amostras de água foram consideradas tóxicas quando o fator de toxicidade foi maior do que 1 .

\section{RESULTADOS E DISCUSSÃO}

\section{Parâmetros físicos e químicos}

Média, desvio padrão, máximo e mínimo valor, e coeficiente de variação dos parâmetros físicos e químicos da água do Ribeirão Samambaia estão apresentados na Tabela 3.

A temperatura da água durante o período de estudo variou de 21,41 a $22,74^{\circ} \mathrm{C}$ (Tabela 3 ) e aumentou sentido montante da cidade de São Pedro para jusante, provavelmente devido à transferência de calor do ar para a água, uma vez que as coletas iniciaram sempre da montante para a jusante no período da manhã.

De acordo com a Resolução no 357 do Conselho Nacional do Meio Ambiente (CONAMA) (BRASIL, 2005), para a preservação da biota, ambientes aquáticos brasileiros de água doce devem ter $\mathrm{pH}$ variando de 6 a 9. No presente estudo, os valores médios de $\mathrm{pH}$ variaram de 7,19 a 7,26 (Tabela 3), estando, dessa forma, dentro do permitido pela legislação brasileira.

Para oxigênio dissolvido, a Resolução no 357 do CONAMA também estabelece limites permissíveis e, nesse caso, valores $\leq 6,0 \mathrm{mg} \cdot \mathrm{L}^{-1}$ não são desejáveis (BRASIL, 2005). Dentre os locais amostrados, somente aquele localizado à jusante da cidade de São Pedro apresentou valor médio menor do que o permitido pela legislação (Tabela 3). Esse baixo valor de oxigênio dissolvido, quando comparado com os outros locais, está associado à sua localização, já que toda a descarga de efluentes domésticos provenientes da cidade atinge esse local, ocasionando diminuição da concentração desse parâmetro por meio do consumo da matéria orgânica pela fauna bacteriana. Resultados similares a esse foram encontrados por Blume et al. (2010). Nesse estudo, os autores observaram decréscimo das concentrações de oxigênio à jusante do Rio dos Sinos, localizado no estado do Rio Grande do Sul, e atribuíram isso às atividades como agricultura, pecuária e lançamentos de esgotos.

Para condutividade, fenóis e surfactantes, observou-se aumento dos valores da montante para jusante da cidade, com valores mais elevados no último local (Tabela 3 ). Assim como para o oxigênio dissolvido, esses três parâmetros estão relacionados às descargas de efluentes na cidade de São Pedro. Para fenóis e surfactantes, a presença de sabão e detergentes nos efluentes pode ter influenciado os altos valores apresentados no último local. Blume et al. (2010) também observaram que valores de condutividade aumentaram da montante para jusante do Rio dos Sinos.

O impacto antropogênico em um ambiente aquático também pode ser avaliado por meio da demanda bioquímica de oxigênio. Para essa variável, segundo a Resolução n 357 do CONAMA, ambientes aquáticos brasileiros não devem apresentar valores maiores ou iguais a $5 \mathrm{mg} \cdot \mathrm{L}^{-1}$ (BRASIL, 2005). No presente estudo, observou-se aumento da concentração no sentido da montante para a jusante da cidade, com valor acima do limite estabelecido pela legislação no último local de amostragem (Tabela 3), demonstrando mais uma vez a baixa qualidade da água nesse local.

Os valores da concentração de clorofila-a encontrados nas amostras de água durante o período de amostragem estão apresentados na Tabela 4. De acordo com a Resolução no 357 do CONAMA, valores de clorofila-a para ambientes aquáticos brasileiros não devem ser maiores do que $10 \mu \mathrm{g} . \mathrm{L}^{-1}$ (BRASIL, 2005). No presente estudo, observou-se que em todos os locais amostrados os valores encontrados estão dentro do permitido pela legislação.

A partir dos valores de clorofila-a observados nas amostras de água, foi possível determinar o IET e, nesse caso, os resultados estão apresentados na Tabela 5.

Tabela 3 - Média, desvio padrão, menor e maior valor e coeficiente de variação da temperatura da água, condutividade, pH, oxigênio dissolvido, demanda bioquímica de oxigênio, fenol e surfactante observados nos locais de amostragens de janeiro a dezembro de 2011.

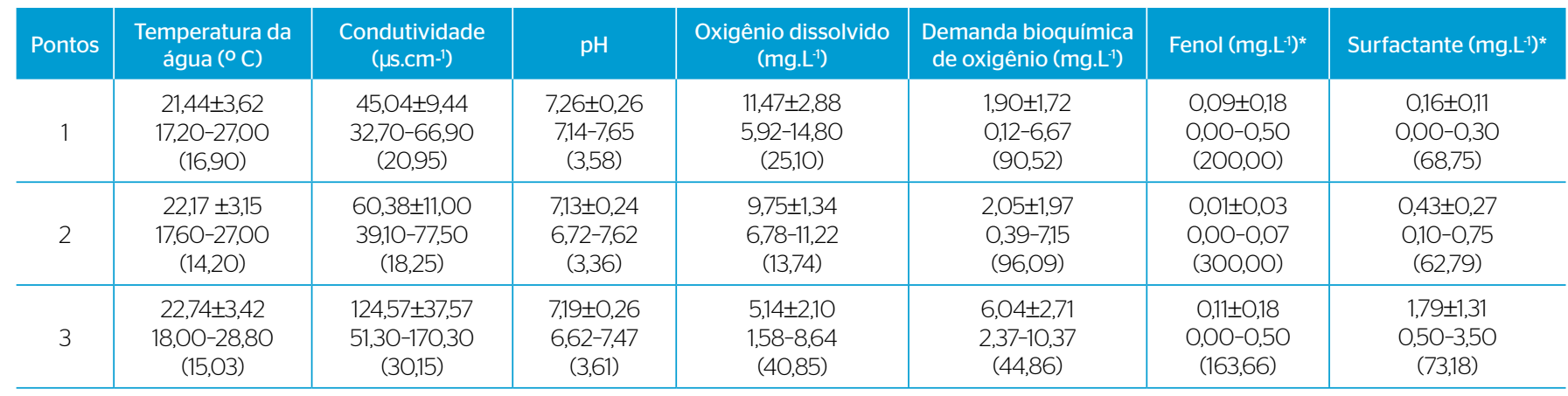

*Valores observados de janeiro a julho de 2011. 
Posteriormente à determinação desses valores foi possível classificar o IET de acordo com Lamparelli (2004), conforme apresentado na Tabela 6. Observa-se que a maioria dos locais amostrados foi classificada como ultraoligotrófica, ou seja, ausência de eutrofização, exceto nas amostras de água coletadas dentro da cidade de São Pedro no mês de agosto (mesotrófico) e setembro (oligotrófico) e à jusante da cidade também no mês de setembro (oligotrófico) (Tabela 6).

A eutrofização, que se refere ao enriquecimento por nutrientes (principalmente nitrogênio e fósforo) e matéria orgânica, tem sido um problema generalizado observado nos ambientes aquáticos pelas atividades antrópicas nas bacias hidrográficas (CLOERN, 2001). Entre algumas das várias causas da eutrofização, o uso de fertilizantes na agricultura e a descarga de efluentes industriais e domésticos não tratados merecem destaque (BOESCH, 2002), no entanto, a entrada de nutrientes pode também se dar naturalmente (WETZEL, 2001). Dentre as consequências para o ambiente estão a perda de vegetação aquática submersa, depleção

Tabela 4 - Concentração de clorofila-a presente nas amostras de água coletadas em diferentes locais de amostragens no Ribeirão Samambaia de abril a dezembro de 2011.

\begin{tabular}{|c|c|c|c|c|c|c|c|c|c|}
\hline \multirow{3}{*}{ Pontos } & \multicolumn{9}{|c|}{ Concentração $\left(\mu \mathrm{g} \cdot \mathrm{L}^{-1}\right)$ de clorofila-a } \\
\hline & \multicolumn{9}{|c|}{ Meses } \\
\hline & Abr & Mai & Jun & Jul & Ago & Set & Out & Nov & Dez \\
\hline 1 & 0,06 & 0,11 & 0,06 & 0,11 & 0,22 & 0,28 & 0,06 & 0,06 & 0,056 \\
\hline 2 & 0,11 & 0,11 & 0,28 & 0,28 & 1,74 & 1,06 & 0,56 & 0,22 & 0,056 \\
\hline 3 & 0,34 & 0,28 & 0,39 & 0,39 & 0,33 & 1,06 & 0,11 & 0,11 & 0,39 \\
\hline
\end{tabular}

Tabela 5 - Índice de estado trófico determinado nas amostras de água coletadas em diferentes locais de amostragens no Ribeirão Samambaia de abril a dezembro de 2011.

\begin{tabular}{c|c|c|c|c|c|c|c|c|c}
\hline \multirow{2}{*}{ Pontos Índice de estado trófico } \\
\cline { 2 - 11 } & \multicolumn{10}{|c}{ Meses } \\
\cline { 2 - 10 } & Abr & Mai & Jun & Jul & Ago & Set & Out & Nov & Dez \\
\hline 1 & 25,15 & 31,00 & 25,15 & 31,00 & 37,01 & 39,10 & 25,10 & 25,10 & 25,10 \\
\hline 2 & 31,00 & 31,00 & 39,10 & 37,01 & 54,90 & 50,60 & 25,10 & 37,01 & 25,10 \\
\hline 3 & 40,70 & 39,10 & 41,90 & 41,90 & 40,70 & 50,60 & 31,00 & 31,00 & 41,90 \\
\hline
\end{tabular}

Tabela 6 - Índice de estado trófico determinado nas amostras de água coletadas em diferentes locais de amostragens no Ribeirão Samambaia durante abril a dezembro de 2011.

\begin{tabular}{c|c|c|c|c|c|c|c|c|c}
\multicolumn{10}{c}{ Índice de estado trófico } \\
\cline { 2 - 10 } Pontos & \multicolumn{10}{c}{ Meses } \\
\cline { 2 - 9 } & Abr & Mai & Jun & Jul & Ago & Set & Out & Nov & Dez \\
\hline 1 & Ultra & Ultra & Ultra & Ultra & Ultra & Ultra & Ultra & Ultra & Ultra \\
\hline 2 & Ultra & Ultra & Ultra & Ultra & Meso & Oligo & Ultra & Ultra & Ultra \\
\hline 3 & Ultra & Ultra & Ultra & Ultra & Ultra & Oligo & Ultra & Ultra & Ultra \\
\hline Ultra: ultraoligotrófico; meso: mesotrófico; oligo: oligotrófico.
\end{tabular}

de oxigênio, alteração da composição e estrutura das comunidades e perda de biodiversidade (GLIBERT et al., 2010).

De acordo com os valores determinados de IET com ponderação para clorofila-a, o Ribeirão Samambaia não se apresenta eutrofizado. No entanto, é extremamente importante considerar que a presença de contaminantes nas águas desse ambiente pode estar mascarando os resultados pela inibição do crescimento algáceo e, dessa forma, contribuindo para a determinação de baixos valores de clorofila-a.

Para Elser e Bennett (2011), com o aumento da população ao longo dos anos, espera-se que a eutrofização dos ambientes aquáticos se intensifique nas próximas décadas devido principalmente às atividades antrópicas, sendo dessa forma importante a aplicação desse índice na avaliação de ecossistemas aquáticos.

Affonso, Barbosa e Novo (2011), assim como no presente estudo, utilizaram o parâmetro clorofila-a para determinar o IET do Lago Grande de Curaí, Pará, e encontraram valores extremamente altos para clorofila-a, e, dessa forma, altos valores de IET foram determinados. É importante destacar que o estudo de Affonso, Barbosa e Novo (2011) ocorreu em um lago, ou seja, um ambiente lêntico, diferentemente do presente trabalho, que ocorreu em um ambiente lótico onde a vazão e a extensão podem ser fatores determinantes para a determinação de baixos valores de clorofila-a. Ainda nesse estudo, os autores observaram maiores valores de IET no período de chuvas, e concluíram que o escoamento de nutrientes para dentro do lago pode ter contribuído para o processo de eutrofização.

Resultados similares ao encontrado por Affonso, Barbosa e Novo (2011) foram também descritos por Alves et al. (2012), que observaram valores mais altos de IET no Rio Arari (Ilha do Marajó, Pará) no período chuvoso. Embora no presente estudo não tenham sido relatados dados de pluviosidade, durante o período de amostragem não foi observada precipitação e, nesse caso, pode-se induzir que a escassez de chuvas pode estar aliada à presença de contaminantes conforme discutido anteriormente, podendo ter sido responsável pelos baixos valores de IET.

A Companhia de Tecnologia e Saneamento Ambiental do Estado de São Paulo (CETESB) avalia a qualidade dos principais rios pertencentes às bacias hidrográficas do estado. Para determinação do IET, a CETESB leva em consideração tanto concentrações de clorofila-a como de fósforo. No relatório de 2012 divulgado pela CETESB, os valores de clorofila-a do Rio Piracicaba variaram de 6,4 a 7,7 $\mu \mathrm{g} . \mathrm{L}^{-1}$ com média de 6,84 $\mu \mathrm{g} . \mathrm{L}^{-1}$, abaixo do limite estabelecido pelo CONAMA, assim como no presente trabalho. Valores de IET variaram de 56,0 a 60,0 com valor médio de 58,5, o que o caracterizou como mesotrófico. No entanto, no presente trabalho, utilizou-se somente o parâmetro clorofila-a, diferentemente da CETESB. Assim, os resultados encontrados pela CETESB podem ter apresentado maiores valores de IET devido à avaliação em conjunto com o fósforo total. Porém, pesquisadores têm mostrado que a relação entre fósforo e clorofila-a na determinação do IET não tem seguido um padrão, como demonstra Maranho (2012) em uma avaliação da qualidade da água do Rio Corumbataí, São Paulo. 
No trabalho conduzido por Maranho (2012), os valores de IET foram maiores quando determinados somente por meio da concentração de clorofila-a, quando comparados aos encontrados pela determinação de fósforo. Pela determinação de baixas concentrações de fósforo no Rio Corumbataí, quando o IET foi determinado por meio dos dois parâmetros, o Rio Corumbataí apresentou-se como ultraoligotrófico na maior parte do período amostrado e na maioria dos locais.

\section{Teste de toxicidade com $D$. magna}

Os resultados do teste de toxicidade das amostras de água coletadas no Ribeirão Samambaia de janeiro a dezembro de 2011 estão apresentados na Tabela 7.

No primeiro e no segundo mês de avaliação (janeiro e fevereiro) observou-se toxicidade da amostra de água coletada à jusante da cidade de São Pedro, já que o fator de toxicidade foi igual a 4. Já no mês de março, a água coletada em todos os locais apresentou toxicidade, no entanto a amostra de água dos pontos 2 e 3 foi mais tóxica, comparada à da montante da cidade de São Pedro. No mês de abril, somente a amostra de água coletada após a cidade de São Pedro apresentou toxicidade. Não foi observada toxicidade entre os meses de março e dezembro de 2011 para nenhum ponto amostrado, no entanto após a exposição de 48 horas os microcrustáceos apresentavam maior crescimento, coloração mais forte e melhor aparência comparados aos organismos expostos à água dos outros locais. A razão para isso pode ser devido à quantidade de matéria orgânica presente após a cidade, podendo ser comprovada pelos valores médios da demanda bioquímica

Tabela 7 - Toxicidade das amostras de água para Daphnia magna coletadas em três locais de amostragens no Ribeirão Samambaia de janeiro a dezembro de 2011.

\begin{tabular}{c|c|c|c|c|c|c|c|c|c|c|c|c|}
\multicolumn{10}{c|}{} & \multicolumn{10}{c}{ Mator de toxicidade } \\
\cline { 2 - 14 } Pontos & \multicolumn{10}{c|}{ Meses } \\
\cline { 2 - 14 } & Jan & Fev & Mar & Abr & Mai & Jun & Jul & Ago & Set & Out & Nov & Dez \\
\hline 1 & 1 & 1 & 4 & 1 & 1 & 1 & 1 & 1 & 1 & 1 & 1 & 1 \\
\hline 2 & 1 & 1 & 8 & 1 & 1 & 1 & 1 & 1 & 1 & 1 & 1 & 1 \\
\hline 3 & 4 & 4 & 8 & 4 & 1 & 1 & 1 & 1 & 1 & 1 & 1 & 1 \\
\hline
\end{tabular}

de oxigênio, que foram bem superiores quando comparados com aqueles apresentados em amostras coletadas à montante e dentro da cidade. De acordo com Knie e Lopes (2004), D. magna é um organismo que atua na cadeia alimentar como consumidor primário e alimenta-se por filtração de material orgânico particulado, o que reforça essa hipótese. Para Salonem e Hammar (1986), os resultados do teste de toxicidade podem ser influenciados pela existência de nutrientes em maior quantidade em relação aos agentes tóxicos.

No presente estudo, a avaliação da qualidade da água do Ribeirão Samambaia por meio de teste de toxicidade com D. magna apresentou resultados de toxicidade somente nos quatro primeiros meses, e, dentre os locais amostrados, a jusante da cidade de São Pedro merece destaque, conforme já discutido anteriormente. Além da baixa qualidade da água desse local, evidenciada pelos ensaios ecotoxicológicos, as análises dos parâmetros físicos e químicos mostraram a mesma situação. De acordo com Lima e Zakia (2004), no Brasil, efluentes urbanos são despejados muitas vezes em sistemas aquáticos naturais, criando condições inadequadas da qualidade da água à jusante de um centro urbano.

Resultados similares aos apresentados no presente trabalho foram observados por Bollmann e Edwiges (2008), que avaliaram a qualidade da água do Rio Belém, Curitiba, e concluíram, através do índice de qualidade de água, que a qualidade diminuiu da montante para a jusante da cidade em razão dos lançamentos de efluentes domésticos oriundos da cidade. Botelho et al. (2013) observaram toxicidade crônica da água do Rio Piracicaba, São Paulo, para os microcrustáceos Ceriodaphnia dubia e Ceriodaphnia silvestrii em alguns locais de amostragens próximos à cidade de Americana e Piracicaba, reforçando a influência dos efluentes domésticos e industriais na qualidade da água.

\section{CONCLUSÃO}

O presente estudo se propôs a avaliar a qualidade da água do Ribeirão Samambaia (São Pedro, São Paulo, Brasil) através da determinação de parâmetros físicos e químicos, IET e teste de toxicidade com D. magna. De acordo com os resultados apresentados, foi observada baixa qualidade desse recurso hídrico após a cidade de São Pedro, provavelmente em razão da descarga de efluentes domésticos provenientes dessa cidade.

\section{REFERÊNCIAS}

ABNT - ASSOCIAÇÃO BRASILEIRA DE NORMAS TÉCNICAS. (1992) NBR 12614. Águas: determinação da demanda bioquímica de oxigênio (DBO), método de incubação (20 C, cinco dias). Rio de Janeiro: ABNT. 5 p.

ABNT - ASSOCIAÇÃO BRASILEIRA DE NORMAS TÉCNICAS. (2003) NBR 12713. Ecotoxicologia aquática: toxicidade aguda, método de ensaio com Daphnia spp. (Cladocera, crustacea). Rio de Janeiro: ABNT. 17 p.

AFFONSO, A.G.; BARBOSA, C.; NOVO, E.M.L.M. (2011) Water quality changes in floodplain lakes due to the Amazon River flood pulse: Lago Grande de Curuaí (Pará). Brazilian Journal of Biology, v. 71 n. 3, p. 601-610. 
ALVES, I.C.C.; EL-ROBRINI, M.; SANTOS, M.L.S.; MONTEIRO, S.M.; BARBOSA, L.P.F.; GUIMARÃES, J.T.F. (2012) Qualidade das águas superficiais e avaliação do estado trófico do Rio Arari (Ilha de Marajó, norte do Brasil). Acta Amazonica, v. 42, n. 1, p. 115-124.

ANDERSON, B.G. (1944) The toxicity thresholds of various substances found in industrial wastes as determined by the use of Daphnia magna. Sewage Works Journal, v. 16, n. 6, 1944, p. 1156-1165.

BLUME, K.K.; MACEDO, J.C:; MENEGUZZI, A.; SILVA, L.B.; QUEVEDO, D.M.; RODRIGUES, M.A.S. (2010) Water quality assessment of the Sinos River, Southern Brazil. Brazilian Journal of Biology, v. 70, n. 4, p. 1185-1193.

BOESCH, D.F. (2002) Challenges and opportunities for science in reducing nutrient over-enrichment of coastal ecosystems. Estuaries, v. 25, n. 4, p. 886-900.

BOLLMANN, H.A. \& EDWIGES, T. (2008) Avaliação da qualidade das águas do Rio Belém, Curitiba-PR, com o emprego de indicadores quantitativos e perceptivos. Engenharia Sanitária e Ambiental, v. 13, n. 4, p. 443-452.

BOTELHO, R.G.; MACHADO NETO, L.; OLINDA, R.A.; DIAS, C.T.; TORNISIELO, V.L. (2012) Water quality assessment in Piracicamirim Creek upstream and downstream a sugar and ethanol industry through toxicity tests with cladocerans. Brazilian Archives of Biology and Technology, v. 55, n. 4, p. 631-636.

BOTELHO, R.G.; ROSSI, M.L.; MARANHO, L.A.; OLINDA, R.A.; TORNISIELO, V.L. (2013) Evaluation of surface water quality using an ecotoxicological approach: a case study of the Piracicaba River (São Paulo, Brazil). Environmental Science and Pollution Research International, v. 20, n. 7, p. 4382-4395.

BRASIL. (2005) Ministério do Meio Ambiente. Conselho Nacional do Meio Ambiente. Resolução no 357, de 17 de março de 2005. Dispõe sobre a classificação dos corpos de água e diretrizes para o seu enquadramento, bem com estabelece as condições e padrões de lançamento de efluentes, e dá outras providências. Diário Oficial da União, Brasília, DF, 18 mar. 2005. Seção 1, p. 58-63.

CAIRNS JUNIOR, J. (2002) Environmental monitoring for the preservation of global biodiversity: the role in sustainable use of the planet. International Journal of Sustainable Development and World Ecology, v. 9, n. 2, p. 135-150.

CARLSON, R.E. (1977) A trophic state index for lakes. Limnology and Oceanography, v. 22, n. 2, p. 361-369.

CARPI JUNIOR, S.; CARRARA, S.L.; BISCALCHIM NETTO, C. (2010) Impasses no planejamento ambiental da estância turística de São Pedro - SP. Climatologia e Estudos da Paisagem, v. 5, n. 1, p. 19-38.

CLOERN, J.E. (2001) Our evolving conceptual model of the coastal eutrophication problem. Marine Ecology Progress Series, v. 210 , p. 223-253.

ELSER, J. \& BENNETT, E. (2011) Phosphorus cycle: a broken biogeochemical cycle. Nature, v. 478, n. 7367, p. 29-31.

GLIBERT, P.M.; ALLEN, J.I.; BOUWMAN, A.F.; BROWN, C.W.; FLYNN, K.J.; LEWITUS, A.J.; MADDEN, C.J. (2O1O) Modeling of HABS and eutrophication: status, advances, challenges. Journal of Marine Systems, v. 83, n. 3-4, p. 262-275.

JARDIM, G.M.; ARMAS, E.D.; MONTEIRO, R.T.R. (2008) Ecotoxicological assessment of water and sediment of the Corumbataí River, SP, Brazil. Brazilian Journal of Biology, v. 68, n. 1, p. 51-59.

JUMA, D.W.; WANG, H.; LI, F. (2O14) Impacts of population growth and economic development on water quality of a lake: case study of Lake Victoria Kenya water. Environmental Science and Pollution Research, v. 21, n. 8, p. 5737-5746.

KNIE, J.L.W. \& LOPES, E.W.B. (2004) Testes ecotoxicológicos: métodos, técnicas e aplicações. Florianópolis: FATMA/GTZ. 289 p.

LAMPARELLI, M.C. (2004) Grau de trofia em corpos d'água do estado de São Paulo: avaliação dos métodos de monitoramento - São Paulo. Tese (Doutorado) - Instituto de Biociências da Universidade de São Paulo, São Paulo.

LIMA, W.P. \& ZAKIA, M.J.B. (2004) Hidrologia de matas ciliares. In: RODRIGUES, RR.; LEITÃO-FILHO, H.F. (Eds) Matas ciliares: conservação e recuperação. São Paulo: Editora USP. p. 33-44.

MARANHO, L.A. (2012) Avaliação da qualidade da água do rio Corumbataí (SP) por meio de variáveis bióticas e abióticas. Tese (Doutorado) - Centro de Energia Nuclear na Agricultura, Universidade de São Paulo, Piracicaba.

OECD - ORGANIZATION FOR ECONOMIC CO-OPERATION AND DEVELOPMENT. (2012) Test No 211: Daphnia magna reproduction test. OECD Guidelines for the Testing of Chemicals, Section 2. OECD. 25 p.

PALMA, P.; ALVARENGA, P.; PALMA, V.; MATOS, C; FERNANDES, R.M.; SOARES, A.; BARBOSA, I.R. (2O10) Evaluation of surface water quality using an ecotoxicological approach: a case study of the Alqueva Reservoir (Portugal). Environmental Science and Pollution Research International, v. 17, n. 3, p. 703-716.

PALMA, P.; LEDO, L.; SOARES, S.; BARBOSA, I.R.; ALVARENGA, P. (2O14) Integrated environmental assessment of freshwater sediments: a chemical and ecotoxicological approach at the Alqueva reservoir. Environmental Geochemistry and Health, v. 36, n. 2, p. 209-223.

SALONEM, K. \& HAMMAR, T. (1986) On the importance of dissolved organic matter in the nutrition of zooplankton in some lake waters. Oecologia, v. 68, n. 2, p. 246-253.

VIEIRA, J.M.P.; PINHO, J.L.S.; DIAS, N; SCHWANENBERG, D; VAN DEN BOOGAARD, H.F.P. (2013) Parameter estimation for eutrophication models in reservoirs. Water Science and Technology, v. 68, n. 2, p. 319-327.

WALSH, C.J.; FLETCHER, T.D.; LADSON, A.R. (2005) Stream restoration in urban catchments through redesigning storm water systems: looking to the catchment to save the stream. Journal of the North American Benthological Society, v. 24, n.3, p. 690-705.

WETZEL, R.G. (2001) Limnology: lake and river ecosystems. 3 ed. San Diego: Elsevier. 1006 p. 